\title{
PREDICCIÓN DE DESERCIÓN Y ÉXITO EN ESTUDIANTES. CASO DE ESTUDIO: INGENIERÍA AGROINDUSTRIAL DE LA UNI NORTE, NICARAGUA, 2011-2015
}

\section{PREDICTION OF DESERTION AND SUCCESS IN STUDENTS. CASE STUDY: AGROINDUSTRIAL ENGINEERING OF UNI NORTE, NICARAGUA, 2011-2015}

\author{
L. M. Dicovskiy Riobóo ${ }^{1}$, M. E. Pedroza Pacheco ${ }^{2}$ \\ ${ }^{1}$ Universidad Nacional de Ingeniería, Sede Regional Norte, \\ luis.dicovskiy@norte.uni.edu.ni \\ ${ }^{2}$ Universidad Nacional Autónoma de Nicaragua, Managua, \\ hppedroza@gmail.com
}

(recibido/received: 21-03-2018; aceptado/accepted: 01-07-2018)

\begin{abstract}
RESUMEN
Se hizo uso de estadística univariada y multivariada, para buscar patrones de rendimiento académico, que permitieran de forma temprana predecir la deserción y el éxito, al final de la carrera, en 7 generaciones de estudiantes universitarios de ingeniería agroindustrial en la UNI sede Norte, Nicaragua. Por medio del análisis discriminante, aplicado a las calificaciones del primer semestre de primer año de la carrera, se pudo clasificar los estudiantes que llegan a quinto año de forma exitosa o no, con un alto nivel de acierto, $79 \%$. Las matemáticas en primer lugar y luego las químicas fueron las asignaturas de mayor peso para predecir el éxito o fracaso final en la carrera.

Palabras claves: Análisis multivariado discriminante; Estudio predictivo; Deserción; Éxito; Ingeniería agroindustrial.

ABSTRACT

Univariate and multivariate statistics were used to look for patterns of academic performance that would allow early prediction of dropout and success at the end of the career in 7 generations of university students of agro-industrial engineering at the UNI North Campus, Nicaragua. By means of the discriminant analysis, the score academic of the first semester of first year of the race, allowed to classify the students that arrive to fifth year of successful form or not, with a high level of success, $79 \%$. Mathematics first and then chemistry were the most important subjects to predict success or failure in the final race.
\end{abstract}

Keywords: Multivariate; Discriminant; Desertion; Success; Agroindustrial engineering. 


\section{M. Dicovskiy Riobóo y M. E. Pedroza Pacheco}

\section{INTRODUCCIÓN}

"La estadística nos permite, explicar las condiciones regulares en los fenómenos de tipo aleatorio, que componen buena parte de nuestro mundo" (Ferreiro y Fernández, 1988). Con este trabajo, a partir de una base de datos académica, se buscó encontrar por medio de estadística univariada y multivariada, patrones de rendimiento académico que permitiesen de forma temprana predecir la deserción y el éxito, en estudiantes universitarios de ingeniería agroindustrial de la Universidad Nacional de Ingeniería, UNI, sede Norte. Un conocimiento de este tipo, permitiría acciones al inicio de la carrera que puedan mejorar, e incrementar los casos de éxito en el egreso a partir de las calificaciones de su primer año académico.

Una de las dimensiones más importantes en el proceso de enseñanza-aprendizaje la constituye el rendimiento académico del alumno. El rendimiento académico de un estudiante universitario es la resultante de una multiplicidad de factores, que van desde los personales, hasta los dependientes de la institución y sus docentes, la definición operativa del rendimiento académico se puede establecer según los criterios de rendimiento inmediato y diferido (Ruiz, et al., 2010). Los rendimientos inmediatos son: el éxito en titularse en un tiempo establecido, las tasas de presentación a exámenes y las calificaciones o notas. El rendimiento diferido tiene que ver con la utilidad o aplicación en la vida social, este concepto es mucho más complejo de evaluar (Tejedor, 2003).

Respecto al rendimiento académico y su importancia, Herrera García, et al., (1999) comentaron que "la problemática del bajo rendimiento académico universitario constituye un grave problema social, con importantes repercusiones personales y familiares. Repercusiones que, de alguna manera, se podrían amortiguar si se lograse poner los medios adecuados para reducir el fracaso en los estudios". García Jiménez, et al., (2000) explican que "el rendimiento académico se concibe como un constructo en el que no sólo se contemplan las aptitudes y la motivación del alumno sino también otras variables intervinientes como los aspectos docentes, la relación profesor-alumno, el entorno familiar, etc.”

Sobre la importancia de las notas que los estudiantes obtienen de forma temprana, tenemos que un estudio en la Universidad Nacional de Córdoba realizado por Goldenhersch y citado por Merlino y Ayllon, (2016), el cual determinó que, el "primer año de la universidad está fuertemente correlacionado con la mayoría de las variables que muestran la historia preuniversitaria del estudiante, a saber: escuela secundaria, ocupación de los padres, educación de los mismos, sexo, con quién vive y cómo costea sus estudios" (Merlino y Ayllon, 2016). Una investigación con una muestra de 175 universitarios de primer año de la UCM, España, concluyó que: el rendimiento previo es un buen predictor del rendimiento futuro, y la asistencia con la participación son variables con un peso importante en la predicción del rendimiento (García Jiménez, et al., 2000).

La evolución en la investigación educativa viene de la mano de dos revoluciones. Por un lado, se desarrollan modelos integrados para estudiar las relaciones entre constructos no directamente observables insertos en contextos complejos. Y por otro, el desarrollo técnico-científico del software para el análisis de datos que ha permitido someter a prueba estos modelos complejos (Castro y Lizasoain, 2012). El uso del análisis estadístico a través de la utilización de funciones discriminante se presenta como "un método alternativo, a la regresión múltiple, para ayudar a tomar decisiones con más información y para predecir el posible éxito del alumno en cursos específicos" (Martinez, 2005).

Según Balzarini, y otros, (2008) el análisis discriminante es "útil para: 1) discriminar, en base a las variables seleccionadas grupos definidos a priori y poder representar a las observaciones en un espacio donde las diferencias entre grupos sean máximas y 2) clasificar nuevos casos en los grupos establecidos a priori sobre la base de una regla de clasificación basada en las variables independientes".

El análisis discriminante implica obtener una combinación lineal de dos, o más, variables independientes que discrimine mejor entre los grupos definidos a priori. La discriminación se lleva a cabo estableciendo las

Nexo Revista Científica / Vol. 31, No. 01, pp. 16-27 / Junio 2018 


\section{M. Dicovskiy Riobóo y M. E. Pedroza Pacheco}

ponderaciones del valor teórico para cada variable de tal forma que maximicen la varianza entre-grupos frente a la varianza intra-grupos (Hair, et al., 1999).

Estudiando el comportamiento de primer y último curso de estudiantes de la Universidad de Granada, España, tratando de vincular factores académicos estrategias y estilos de aprendizaje por medio de Análisis de la Variancia Multivariada y Análisis Discriminante se encontró que había diferencias significativas en los perfiles de estrategias o estilos de aprendizaje en función del grupo de rendimiento alto o bajo al que pertenecía el sujeto (Cano y Justicia, 1993).

En un estudio en la Universidad de Salamanca se hizo aplicación del análisis discriminante a una base de datos de estudiantes para caracterizar los estudiantes de alto y bajo rendimiento académico. Este análisis encontró que el perfil de los sujetos con mejor rendimiento universitario y en orden de importancia se caracterizó por lo siguiente: alumnos de alto rendimiento en la Enseñanza Media, con alta valoración en sus hábitos de estudio, que asisten regularmente a las clases que se imparten, con un nivel alto de satisfacción ante la carrera elegida, edad, motivados culturalmente desde el ámbito familiar, con una actitud positiva hacia la Universidad y un concepto de autoeficacia elevado (Herrera García, et al., 1999).

En la UNAM, México, con datos de 200 estudiantes de posgrado, se construyó un modelo predictivo de las condiciones asociadas al éxito académico para determinar el perfil del estudiante exitoso. Tres variables se destacaron en la función discriminante: tipo de beca, estado civil y el y el tiempo de dedicación al posgrado (Martínez-González, et al., 2003). Con un grupo de 121 egresados de la carrera de Medicina, en el norte de México, se encontró que la correlación entre el promedio general del examen de conocimientos al ingreso y el rendimiento académico al término del octavo semestre resultó de 0,409 ( $p<0,01)$ (Gómez-López, et al., 2012).

Investigadores de la Universidad de Compostela, con datos de 1.401 alumnos de Primaria, $5^{\circ}$ y $6^{\circ}$, y de la ESO, Enseñanza Secundaria Obligatoria, $1^{\circ}$ y $2^{\circ}$, con el objetivo de determinar que variables asociadas teóricamente al logro académico, podían a discriminar entre aquellos estudiantes matriculados en enseñanzas obligatorias, ya sean autóctonos o de origen inmigrante, que aprueban o suspenden las asignaturas del currículo que llevan por nombre Lengua Castellana y Literatura y Lengua Gallega y Literatura. Encontraron que las variables que tenían un mayor peso discriminante en el grupo de estudiantes suspensos fueron: hablar en gallego y edad, mientras que entre los aprobados resultan ser "el ambiente de aprendizaje" y "la conflictividad a nivel familiar" (Santos, Godás, y Lorenzo, 2013).

Una muestra con 749 estudiantes de la Universidad de La Laguna en Tenerife, España, encontraron que, al realizar análisis discriminante, se encontró que el uso de las estrategias de aprendizaje tiene capacidad para discriminar los grupos extremos en tres indicadores de rendimiento (Martín, et al., 2008).

Al analizar las actitudes de los profesores ante las nuevas tecnologías y ante su integración en el aula, un análisis discriminante de uso por grupos actitudinales permitió confirmar diferencias existentes, los profesores del grupo con actitudes positivas se vinculaban al uso de Internet en casa y en el centro, mientras que los grupos con actitudes negativas hacían lo contrario (Gargallo et al., 2006).

En una universidad pública del medio oeste en los Estados Unidos, por medio de análisis discriminante y con cuatro variables cuantitativas de admisión tradicionales como el promedio de pregrado (UGPA), o el Examen de Graduados. Se tuvo mucho éxito al clasificar a los estudiantes que se graduaron exitosamente el $97.9 \%$. Sin embargo, hubo un pobre desempeño al clasificar a los estudiantes que fueron despedidos $16.0 \%$ o abandonaron $4.2 \%$ por su propia cuenta (Hatchett, et al., 2017).

Una investigación en la República de Mauricio, con datos recopilados un mes antes de los exámenes, pudo construir un análisis discriminante lineal que predecía correctamente los resultados del 74 por ciento de los 


\section{M. Dicovskiy Riobóo y M. E. Pedroza Pacheco}

estudiantes de pregrado, categorizándolos en tres categorías: aprobado, reprobado y en riesgo (Rowtho, 2017).

Como antecedente de este trabajo se cita la monografía de titulación de Montenegro, López y Fonseca, del cual el autor fue tutor, donde se aplicó el análisis discriminante, a una cohorte, ingreso 2005 donde se buscaba un modelo predictivo de deserción y éxito en tres carreras de la UNI sede Regional Norte. De forma particular en la carrera de Ing. Agroindustrial, a partir del historial de notas de, 40 estudiantes, con la técnica de análisis multivariado discriminante, se pudo construir un modelo probabilístico que, a partir de las notas obtenidas en el primer año de clases, permitiera clasificar los estudiantes en tres categorías: Desertor, De Riesgo y Exitoso. Estas categorías se definieron como: Desertor, aquel estudiante que al cabo de 5 años no había inscrito ninguna asignatura del último año de su carrera; De Riesgo, aquel estudiante que había inscrito 3 o 2 asignaturas de quinto año; y Exitoso, aquel estudiante que había inscrito 4 o más asignaturas de su carrera de quinto año. En este trabajo utilizando la medida de Mahalanobis cuadrática, con las notas del primer semestre de clases, se predijo con el $77.5 \%$ de éxito, quienes serían exitosos y quienes no (Montenegro, et al., 2011).

\section{MATERIAL Y MÉTODO}

Este estudio fue de tipo observacional, descriptivo, correlacional, analítico de causa-efecto y predictivo. De acuerdo, al tiempo de ocurrencia de los hechos y registro de la información, el estudio es retrospectivo, por el período y secuencia del estudio es longitudinal y (Canales, et al., 1996). De acuerdo a sus características particulares, como en esta investigación, los sujetos de estudio, los estudiantes, no fueron asignados al azar a los grupos de manera predefinida, sino que dichos grupos y sus repeticiones ya estaban prefijados antes del experimento, estos ya están formados de forma independiente, los datos se organizaran de acuerdo a la lógica de un Diseño Cuasi experimental (Hernandez et al., 2014), con datos desbalanceados.

El Sistema de Registro Académico de la Sede UNI Norte de Estelí facilitó de forma anónima, sin identificar nombres, parte de la base de datos histórica, ingresos 2005-2011 de registros académicos de la carrera de Ingeniería Agroindustrial, en formato de tabla en el software Excel, de 327 estudiantes. Para hacer operativa la información se filtró de la base de datos de notas original, los ingresos 2005-2011 correspondientes a los egresos 2009-2015, en total 7 generaciones de estudiantes.

En Excel se reorganizó la información por asignatura y año de aprobación y se llevó a una sola tabla donde cada columna eran las asignaturas. Con las notas de quinto año se creó la variable de clasificación de éxito y fracaso. Luego se llevó la misma tabla a InfoStat. En la Tabla 1, se observa la frecuencia de los estudiantes por año de ingreso que participaron en el análisis.

Tabla 1. Frecuencias de Estudiantes por año de ingreso

\begin{tabular}{ccc}
\hline Ingreso & FA & \multicolumn{1}{l}{ FR } \\
\hline 2005 & 44 & 0.13 \\
2006 & 43 & 0.13 \\
2007 & 49 & 0.15 \\
2008 & 52 & 0.16 \\
2009 & 52 & 0.16 \\
2010 & 55 & 0.17 \\
2011 & 32 & 0.10 \\
\hline
\end{tabular}

Nexo Revista Científica / Vol. 31, No. 01, pp. 16-27 / Junio 2018 


\section{M. Dicovskiy Riobóo y M. E. Pedroza Pacheco}

Se definió la variable de clasificación o agrupamiento, "resultado académico", con las asignaturas de quinto año, teniendo en cuenta el número de clases aprobadas en el último año de la carrera. Así se crean tres categorías: Desertor $=0$ asignaturas aprobadas, en Riesgo $\leq 3$ asignaturas aprobadas, Exitoso $\geq$ a 4 asignaturas aprobadas.

Las variables numéricas utilizadas en la función discriminante fueron las notas finales del I y II Semestre de la carrera. Las asignaturas del I semestre fueron: Matemática I, Química General, Procesos Biológicos, Ingles I, Informática I e Introducción I. Las asignaturas del II semestre fueron: Matemática II, Física I, Química de Alimentos, Cultura de Paz, Ingles II, Informática II e Introducción II. También se incorporó la variable dicotómica Género: mujer $=1$ y varón $=2$.

Para conocer si las asignaturas de primer año de la carrera podían discriminar el éxito o fracaso académico se hizo análisis de variancia univariado y análisis de variancia multivariado, MANOVA, con las asignaturas de primer año tomando como variable de clasificación el resultado académico, cinco años después. Con un Análisis de Correlación Canónica, ACC, se verificó la correlación entre las notas del primer y segundo semestre de primer año.

Para predecir comportamiento final, se hizo Análisis Discriminante con las asignaturas del primer semestre y del primer año de la carrera. La combinación lineal para el análisis discriminante, también conocida como función discriminante, se deriva de una ecuación que adopta la siguiente forma: $Z_{j k}=a+W_{1} X_{1 k}+$ $W_{2} X_{2 k}+W_{3} X_{3 k}+\cdots+W_{n} X_{n k}$. Donde: $Z_{j k}=$ puntuación $Z$, discriminante de la función discriminante $j$, para el objeto $k$; $a=$ constante, $W_{i}=$ ponderación discriminante para la variable independiente $i$; $X_{i k}=$ variable independiente $i$ para el objeto $k$ (Hair, et al., 1999). Las distancias utilizadas para hacer la clasificación fueron la Euclídea y Euclídea ${ }^{2}$. También se construyó un gráfico Biplot de Análisis de Componentes Principales, para integrar visualmente los resultados relevantes.

Para hacer el análisis estadístico de los datos se usó el software InfoStat 2016 versión profesional, en sus rutinas de análisis univariado y multivariado para hacer: análisis de la variancia multivariado, correlaciones canónicas, análisis de componentes principales y análisis discriminante (Di Rienzo et al., 2015).

\section{RESULTADOS Y DISCUSIÓN}

La prueba de análisis de variancia univariado con las variables numéricas: notas finales de primer año y la variable de agrupación final, con tres categorías: desertor, riesgo y exitoso. En todos los casos se separó bien el grupo de desertores, pero se observó que los estudiantes en riesgo y de éxito estaban dentro del mismo grupo, Ver Tabla 2.

Tabla 2. Análisis de la varianza univariado y comparación de promedios

\begin{tabular}{lrllll}
\hline \multicolumn{1}{c}{ Variable } & \multicolumn{1}{c}{ F } & $\boldsymbol{p}$-valor & Desertor & Riesgo & Exitoso \\
\hline Matemática I & 101.82 & $<0.0001$ & $\mathrm{~A}$ & $\mathrm{~B}$ & $\mathrm{~B}$ \\
Química general & 74 & $<0.0001$ & $\mathrm{~A}$ & $\mathrm{~B}$ & $\mathrm{~B}$ \\
Procesos biológicos & 52.99 & $<0.0001$ & $\mathrm{~A}$ & $\mathrm{~B}$ & $\mathrm{~B}$ \\
Ingles I & 39.25 & $<0.0001$ & $\mathrm{~A}$ & $\mathrm{~B}$ & $\mathrm{~B}$ \\
Informática I & 43.63 & $<0.0001$ & $\mathrm{~A}$ & $\mathrm{~B}$ & $\mathrm{~B}$ \\
Introducción I & 54.84 & $<0.0001$ & $\mathrm{~A}$ & $\mathrm{~B}$ & $\mathrm{~B}$ \\
Matemática II & 175.92 & $<0.0001$ & $\mathrm{~A}$ & $\mathrm{~B}$ & $\mathrm{~B}$ \\
Física I & 79.72 & $<0.0001$ & $\mathrm{~A}$ & $\mathrm{~B}$ & $\mathrm{~B}$ \\
\hline
\end{tabular}

Nexo Revista Científica / Vol. 31, No. 01, pp. 16-27 / Junio 2018 


\begin{tabular}{lrllll}
\hline Química de alimentos & 142.33 & $<0.0001$ & A & B & B \\
Cultura de paz & 99.69 & $<0.0001$ & A & B & B \\
Ingles II & 114.91 & $<0.0001$ & A & B & B \\
Informática II & 110.41 & $<0.0001$ & A & B & B \\
Introducción II & $112<0.0001$ & A & B & B \\
\hline Test: LSD de Fisher Medias con una letra comín no son significativamente diferentes $(p>0.05)$ & &
\end{tabular}

Sin embargo, el análisis de variancia multivariado en 4 pruebas equivalentes encontró diferencias significativas. Y bajo la prueba multivariada de separación de grupos por Hotelling, los tres grupos de clasificación final fueron diferentes, ver Tablas 3 y 4.

Tabla 3. Resultados del Análisis de la varianza multivariado

\begin{tabular}{cccccc}
\hline Técnica & Estadístico & F & Gl (num) & Gl (den) & $\boldsymbol{p}$ \\
\hline Pillai & 0.85 & 16.36 & 28 & 624 & $<0.0001$ \\
Wilks & 0.21 & 26.35 & 28 & 622 & $<0.0001$ \\
Lawley-Hotelling & 3.51 & 38.89 & 28 & 620 & $<0.0001$ \\
Roy & 3.43 & 76.55 & 14 & 312 & $<0.0001$ \\
\hline
\end{tabular}

Tabla 4. Prueba de comparación de grupos de Hotelling

\begin{tabular}{lc}
\hline Categoría & Signif. \\
\hline Riesgo & A \\
Exitoso & B \\
Desertor & C \\
\hline Medias con una letra común no son significativamente diferentes $(p>0.05)$
\end{tabular}

Se realizó un Análisis de Correlaciones Canónicas, ACC, con las notas de los dos semestres de primer año. Al hacer el ACC de las asignaturas del primer semestre con las del segundo semestre, el modelo calculó 6 correlaciones lineales canónicas. Fue el mejor modelo la Primera Correlación Lineal, L (1), que es la que se interpreta. Esta primera correlación tuvo un valor muy alto, $\mathrm{R}=0.86 . \mathrm{El} \mathrm{R} \mathrm{R}^{2}=0.71$ indicó que el $71 \%$ de la variabilidad entre ambos semestres estaba siendo explicada por este análisis. Ambos grupos estaban muy vinculados, las notas de las asignaturas del primer semestre explicaron bien las notas de las asignaturas del segundo semestre. Ver la Tabla 5 de Correlaciones Canónicas.

Tabla 5. Correlaciones Canónica primer semestre y segundo semestre de primer año

\begin{tabular}{lcccccr}
\hline & $\mathbf{L}(\mathbf{1})$ & $\mathbf{L}(\mathbf{2})$ & $\mathbf{L}(\mathbf{3})$ & $\mathbf{L}(\mathbf{4})$ & $\mathbf{L}(\mathbf{5})$ & $\mathbf{L}(\mathbf{6})$ \\
\hline $\mathbf{R}$ & $\underline{0.86}$ & 0.47 & 0.37 & 0.26 & 0 & 0.16 \\
$\mathbf{R}^{2}$ & 0.74 & 0.22 & 0.14 & 0.07 & 0 & 0.02 \\
Lambda & 604.94 & 178.03 & 98.9 & 51.77 & 29 & 7.85 \\
gl & 42 & 30 & 20 & 12 & 6 & 2 \\
p-valor & 0 & 0 & $2 \mathrm{E}-12$ & 0.0 & 0 & 0.02 \\
\hline
\end{tabular}

En la Figura 1, el Gráfico Biplot se muestra visualmente que todas las asignaturas del primer semestre crecen en la misma dirección respecto al eje horizontal y que los estudiantes exitosos está cerca de los de riesgo y

Nexo Revista Científica / Vol. 31, No. 01, pp. 16-27 / Junio 2018 
los estudiantes desertores están claramente a la izquierda y separados. Con la categoría Género, el gráfico muestra que hubo más deserción en los varones.

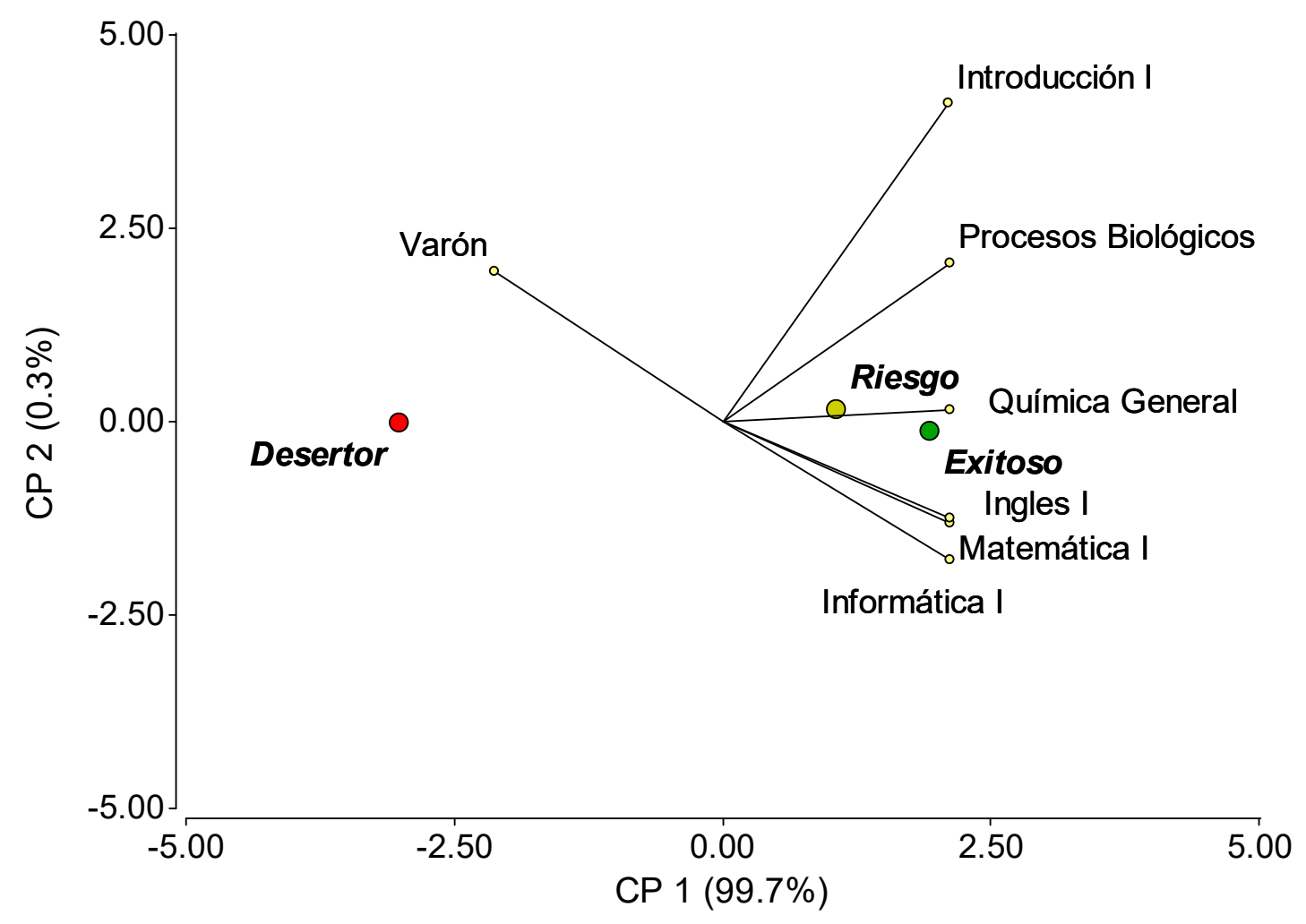

Figura 1. Gráfico Biplot. Asociación del Primer semestre con los grupos de clasificación

Se hizo un Análisis discriminante con notas del primer semestre, en este análisis las variables numéricas consideradas fueron las del primer semestre de primer año: Matemática I, Química General, Procesos Biológicos, Ingles I, Informática I, Introducción I y el Género.

Como hubo tres grupos de clasificación, se generaron dos funciones discriminantes, o sea dos ejes canónicos, en la Tabla 6 se observa que el eje canónico 1 explicó el $99.71 \%$ de la variación entre grupos, una sola función discriminante es suficiente para hacer la clasificación de los individuos.

Tabla 6. Auto valores de las funciones discriminantes canónicas, primer semestre

\begin{tabular}{ccc}
\hline Auto valores & $\mathbf{\%}$ & \% acumulado \\
\hline 0.74 & $\underline{99.71}$ & 99.71 \\
$2.10 \mathrm{E}-03$ & 0.29 & 100 \\
\hline
\end{tabular}

La función discriminante estandarizada permite observar cual es la variable más importante para la discriminación que, este caso fue Matemática I y luego con un valor bastante inferior aparece el Género, ver Tabla 7. 


\section{M. Dicovskiy Riobóo y M. E. Pedroza Pacheco}

Tabla 7. Funciones discriminantes, datos estandarizados con las varianzas comunes del primer semestre

\begin{tabular}{lrr}
\hline Asignatura/Función & $\boldsymbol{I}$ & $\boldsymbol{I I}$ \\
\hline Género & 0.29 & 0.08 \\
Matemática I & $\underline{-0.74}$ & $\underline{-0.39}$ \\
Química General & -0.24 & -0.28 \\
Procesos Biológicos & -0.08 & 1.01 \\
Ingles I & 0.13 & -0.55 \\
Informática I & 0.06 & -0.79 \\
Introducción I & -0.14 & 1.06 \\
\hline
\end{tabular}

En la Tabla 8, que se refiere a la clasificación cruzada, cada fila representó al grupo que pertenece la observación y las columnas al grupo que es asignada la observación. La última columna explicó el \% de error que se tiene en cada grupo. De manera general el \% de error de la clasificación fue alto del 38\%.

Tabla 8. Clasificación cruzada, Tasa de error aparente, con la distancia Euclídea notas primer semestre

\begin{tabular}{lccccc}
\hline Grupo & Desertor & Exitoso & Riesgo & Total & Error (\%) \\
\hline Desertor & 115 & 27 & 44 & 186 & 38.17 \\
Exitoso & 2 & 79 & 50 & 131 & 39.69 \\
Riesgo & 0 & 3 & 7 & 10 & 30.00 \\
Total & 117 & 109 & 101 & 327 & 38.53 \\
\hline
\end{tabular}

Buscando mejorar la clasificación y considerando que Montenegro, et al., (2011) utilizaron una medida cuadrática en su prueba con una sola generación de estudiantes y que Balzarini, et al., (2008) dicen que cuando los datos son normales, una discriminación cuadrática podría ser más adecuada que la función discriminante lineal. Por esto se repitió la prueba con la distancia Euclídea ${ }^{2}$. En este caso el error de clasificación se disminuyó al 21 \%, obteniéndose resultados semejantes a los de Montenegro, et al., (2011), ver Tabla 9.

Tabla 9. Tabla de clasificación cruzada, Tasa de error aparente, con la distancia Eucldea ${ }^{2}$, notas primer semestre

\begin{tabular}{lccccc}
\hline Grupo & Exitoso & Desertor & Riesgo & Total & Error (\%) \\
\hline Exitoso & 107 & 20 & 4 & 131 & 18 \\
Desertor & 38 & 146 & 2 & 186 & 22 \\
Riesgo & 3 & 3 & 4 & 10 & 60 \\
Total & 148 & 169 & 10 & 327 & $\underline{21}$ \\
\hline
\end{tabular}

Estos resultados concuerdan con los observados en China por Zhou et al., (2015), cuando dicen que el éxito académico de los estudiantes en primer año de la carrera juega un papel crítico en su desarrollo general en la universidad.

Al hacer el Análisis discriminante con notas del primer y segundo semestre, las variables consideradas fueron las del primer y segundo semestre de primer año: Matemática I, Química General, Procesos Biológicos, Ingles I, Informática I, Introducción I, Matemática II, Física I, Química de Alimentos, Cultura de Paz, Ingles II, Informática II, Introducción II y Género. En la Tabla 10, se observa que el eje canónico 1 explicó el $98.49 \%$ de la variación entre grupos. 


\section{M. Dicovskiy Riobóo y M. E. Pedroza Pacheco}

Tabla 10. Auto valores de las funciones discriminantes canónicas, primer semestre

\begin{tabular}{lll}
\hline Auto valores & \% & \% acumulado \\
\hline 1.37 & $\underline{98.49}$ & 98.49 \\
0.02 & 1.51 & 100 \\
\hline
\end{tabular}

En la función discriminante estandarizada 1, la variable más importante para la discriminación en primer año fue Matemática II y luego con un valor bastante inferior aparece Química de Alimentos, ambas del segundo semestre ver Tabla 11.

Tabla 11. Funciones discriminantes, datos estandarizados con las varianzas comunes del primer semestre

\begin{tabular}{lrr}
\hline Asignatura/Función & $\mathbf{1}$ & $\mathbf{2}$ \\
\hline Género & 0.1 & -0.01 \\
Matemática i & -0.16 & 0.15 \\
Química General & 0.15 & 0.11 \\
Procesos Biológicos & -0.09 & -0.52 \\
Ingles I & 0.07 & 0.21 \\
Informática I & 0.03 & 0.5 \\
Introducción I & -0.0038 & -0.1 \\
Matemática II & $\underline{-0.55}$ & 0.24 \\
Física I & 0.15 & 1.06 \\
Química de Alimentos & -0.44 & 0.13 \\
Cultura de Paz & 0.04 & -0.26 \\
Ingles II & 0.0021 & -0.49 \\
Informática II & -0.11 & -0.56 \\
Introducción II & -0.21 & -0.3 \\
\hline
\end{tabular}

De manera general el \% de error de la clasificación en los grupos, con las notas de los 2 primeros semestres fue muy semejante al primer semestre, $20 \%$, ver Tabla 12. Para tratar de mejorar la clasificación también se hizo el cálculo con la distancia Euclídea $^{2}$, pero su clasificación no mostró mejora al 20\%.

Tabla 12. Clasificación cruzada, Tasa de error aparente, con la distancia Euclidea ${ }^{2}$, notas primer y segundo semestre

\begin{tabular}{lccccc}
\hline Grupo & Desertor & Exitoso & \multicolumn{1}{c}{ Riesgo } & \multicolumn{1}{c}{ Total } & Error (\%) \\
\hline Desertor & 146 & 29 & 11 & 186 & 22 \\
Exitoso & 5 & 108 & 18 & 131 & 18 \\
Riesgo & 0 & 4 & 6 & 10 & 40 \\
Total & 151 & 141 & 35 & 327 & 20 \\
\hline
\end{tabular}




\section{M. Dicovskiy Riobóo y M. E. Pedroza Pacheco}

\section{CONCLUSIONES}

Por medio de un análisis de variancia univariado y multivariado las notas del primer y segundo semestre del primer año de la carrera, permitieron separar al menos dos grupos de estudiantes, los que eran exitosos en llegar al quinto año de la carrera y los que no lo eran.

El análisis de correlaciones canónicas con las notas finales de las asignaturas del primer semestre y segundo semestre del primer año de la carrera, de forma grupal estuvieron muy correlacionadas. Aquellos estudiantes con buenas o malas notas en el primer semestre mantuvieron en general, su comportamiento en el segundo semestre.

El mejor modelo para discriminar de forma temprana, fueron las notas del primer semestre de primer año, utilizando la distancia Euclidea $^{2}$, que permitieron clasificar los estudiantes que llegan a quinto año de forma exitosa o no, con un alto nivel de acierto, 79\%. Se coincide con Zhou et al., (2015), cuando sugieren que para mejorar la promoción universitaria hay que concentrarse en identificar las formas de incrementar el éxito académico en los estudiantes de primer año

La incorporación de las notas de segundo semestre de primer año, casi no mejoraron la predicción de éxito o fracaso, lo que da entender que con solo las notas del primer semestre del primer año se puede construir un modelo de predicción bastante bueno de éxito o fracaso al finalizar la carrera, cuatros años después.

Las matemáticas en primer lugar y luego las químicas fueron las asignaturas de mayor peso para predecir el éxito o fracaso final de la carrera. Lo que se puede interpretar que fueron las asignaturas de mayor complejidad y en la cuales hay que hacer énfasis para mejorar la retención en la carrera de ingeniería agroindustria.

\section{REFERENCIAS}

Balzarini, M., Gonzalez, L., Tablada, M., Casanoves, F., Di Rienzo, J. y Robledo, C. (2008). Manual del usuario. Córdoba, Argentina: Brujas.

Canales, F., Alvarado, E. y Pineda, E. (1994). Metodología de la investigación, Manual para el desarrollo de personal de salud (Segunda ed.). Washington, D.C: OPS.

Cano, F. y Justicia, F. (1993). Factores académicos, estrategias y estilos de aprendizaje Revista de Psicología General y Aplicada, 46 (1), 89-99.

Castro, M. y Lizasoain, L. (2012). Las técnicas de modelización estadística en la investigación educativa: minería de datos, modelos de ecuaciones estructurales y modelos jerárquicos lineales. Revista Española de Pedagogía, 70 (251), 131-148.

Ferreiro, O. y Fernández, P. (1988). La Estadística, una ciencia en la controversia. Revista Universitaria, 25. Recuperado de http://dta.utalca.cl/estadistica/documentos/articulo4.pdf.

García Jiménez, M., Alvarado Izquierdo, J. y Jiménez Blanco, A. (2000). La predicción del rendimiento académico: regresión lineal versus regresión logística. Psicothema, 12 (2), 248-525.

Gargallo, B., Súarez, J. y Almerich, G. (2006). La influencia de las actitudes de los profesores en el uso de las nuevas tecnologías. Revista Española de Pedagogía, 54 (233), 45-66. 


\section{M. Dicovskiy Riobóo y M. E. Pedroza Pacheco}

Gómez-López, V. M., Rosales-Gracia, S., Marín-Solórzano, G., García-Galaviz, J. L. y Guzmán-Acuña, J. (2012). Correlación entre el examen de selección y el rendimiento académico al término de la carrera de Medicina. Educación Médica Superior, 26 (4), 502-513. Recuperado el 7 de Noviembre de 2017, de http://scielo.sld.cu/scielo.php?script=sci_arttext\&pid=S0864-21412012000400003.

Hair, J., Anderson, R., Tatham, R. y Black, W. (1999). Análisis multivariante (Quinta ed.). Madrid: PRENTICE HALL.

Hatchett, G., Lawrence, C. y Coaston, S. (2017). Re-examination of traditional admissions in predicting academic success in a Counselor Education Program. Int J Adv Counselling, 39, 70-81.

Herrera García, E., Nieto Martín, S., Rodríguez Conde, M. J., Gómez, S. y Cruz, M. (1999). Factores implicados en el rendimiento académico de los alumnos, Universidad de Salamanca. Revista de Investigación Educativa, 17 (2), 413-421.

Martín, E., García, L., Torbay, A. y Rodríguez, T. (Octubre de 2008). Estrategias de aprendizaje y rendimiento académico en estudiantes universitarios. International Journal of Psychology and Psychological Therapy, 8 (3), 401-412.

Martinez, D. (2005). Predicting student outcomes using discriminant function analysis. Annual Meeting of the Research and Planning Group (pág. 22). Lake Arrowhead CA: ERIC. Recuperado el 28 de 11 de 2017, de https://files.eric.ed.gov/fulltext/ED462116.pdf.

Martínez-González, A., Urritia-Aguilar, M., Martínez-Franco, A., Ponce-Rosas, R. y Gil-Miguel, A. (2003). Perfil del estudiante de posgrado con éxito académico en la UNAM. Tarbiya, Revista de Investigación e Innovación Educativa(32), 133-145. Recuperado de http:/www.uam.es/servicios/apoyodocencia/ice/tarbiya/pdf/revistas/Tarbiya032.pdf.

Merlino, A. y Ayllon, S. (2016). Experiencias en investigación dducativa. Córdoba, Argentina: Brujas.

Montenegro, J., López, A. y Fonseca, E. (2011). Automatización de un Sistema Predictivo de Deserción Estudiantil en la UNI Norte, integrado al SIRA. Estelí: UNI Norte. Recuperado de http://ribuni.uni.edu.ni/937/1/26048.pdf.

Rowtho, V. (18 de Julio de 2017). Early detection of at-risk undergraduate students through academic performance predictors. Higher Education Studies, 7(3), 42-54. Recuperado el 28 de 11 de 2017, de https://files.eric.ed.gov/fulltext/EJ1150071.pdf.

Ruiz, G., Ruiz, J. y Ruiz, E. (25 de Abril de 2010). Indicador global de rendimiento. (OEI, Ed.) Revista Iberoamericana de Educación, 52, 1-11.

Santos, M., Godás, A. y Lorenzo, M. (Septiembre Diciembre de 2013). Rendimiento académico y diversidad cultural: el eje lingüístico. Revista Española de Pedagogía, 256, 461-478.

Tejedor, F. (2003). Poder explicativo de algunos determinantes del rendimiento en los estudios universitarios. Revista Española de Pedagogía, 224, 5-32.

Zhou, Y.-X., Ou, C.-Q., Zhao, Z.-T., Wan, C.-S., Guo, C., Li, L. y Chen, P.-Y. (2015). The impact of selfconcept and college involvement on the first-year success of medical students in China. Adv in Health Sci Educ, 20, 163-179. 


\section{SEMBLANZA DE LOS AUTORES}

Luis María Dicovskiy Riobóo: es graduado de Ingeniero Agrónomo por la Universidad Nacional de Rosario, Argentina, hizo especialidad en Mejora Vegetal, en el Instituto de Altos Estudios del Mediterráneo, Zaragoza, España, recibió el título de maestro en Estadística e Investigación de Operaciones por la Universidad de Valencia, España, el título de maestro en Investigación Social Cualitativa por la UPOLI, Nicaragua, actualmente es doctorante de la UNAN Managua en "Gestión y Calidad de la Investigación Científica" y docente de la UNI Sede Regional Norte.

Manuel Enrique Pedroza Pacheco: es graduado de Ingeniero Agrónomo Fitotecnista, en la Facultad de Ciencias Agropecuarias de la UNAN, hoy UNA y Doctor en Ciencias Agrícolas, en la Universidad Agraria de Plovdiv, Bulgaria. Es miembro fundador de la Academia de Ciencias de Nicaragua (ACN). Es el creador del Programa de Maestría en "Métodos de Investigación Científica" y el Programa de Doctorado en "Gestión y Calidad de la Investigación, ambos de la UNAN Managua. Actualmente es profesor titular e investigador de UNAN-Managua. 